\title{
Spirometric evaluation of pulmonary functions of medical students in Nepal
}

\author{
G. B. Nepal', P. K. L. Das' ${ }^{2}$, A. Bhaila ${ }^{3}$ \\ ${ }^{1,3}$ Lecturer, Department of Physiology, KIST Medical College, Nepal, ${ }^{2}$ Professor and Head, Department of Physiology, KIST Medical College, \\ Nepal
}

\section{A B S T R A C T}

Background: Spirometry is vital in screening, diagnosing and monitoring of patients in clinical respiratory medicine. The interpretations of these results depend on comparison with reference values derived from a pool of normal healthy population, which are age, weight, height, gender and ethnicity dependant. Objectives: To establish normative data of lung function indices (FVC, FEV,$F_{1} / F V C$, PEFR and MVV) of healthy adult persons and to find correlation of these data, if any, with age, height, weight and BMI. Methods: Participants ( $n=174$, mean age $19.60 \pm 1.177 \mathrm{yrs}$, height $161.87 \pm 8.572 \mathrm{~cm}$, weight $58.65 \pm 11.190$ $\mathrm{kg}$ and BMI $22.28 \pm 3.159 \mathrm{~kg} / \mathrm{m}^{2}$ ) were recruited from KIST medical college. Spriometry was performed and data were grouped according to age, height, weight, BMI and gender. Results: The mean FVC, FEV 1 , PEFR and MVV of males $(3.58 \pm 0.7241 \mathrm{~L}, 3.34 \pm 0.61 \mathrm{~L}$, $8.41 \pm 1.20 \mathrm{~L} / \mathrm{sec}$ and $141.45 \pm 18.54 \mathrm{~L} / \mathrm{min}$ respectively) were significantly higher than that of females $(2.52 \pm 0.50 \mathrm{~L}, 2.44 \pm 0.44 \mathrm{~L}, 6.72 \pm 0.82 \mathrm{~L} / \mathrm{sec}$ and $106.93 \pm 12.49 \mathrm{~L} / \mathrm{min}$ respectively). However, $\mathrm{FEV}_{1} / \mathrm{FVC}$ ratio was statistically similar in males and females. FVC and FEV , were positively correlated with height and weight in females. PEFR showed correlation with weight and BMI and MVV showed correlation with weight in females. In males, FVC showed positive correlation with height, weight and BMI. FEV 1 and MVV showed maximum correlation with height of male students. Conclusions: Significant increased in PFT parameters were observed in male as compare to female. PFT parameters were mainly influenced by body height and weight in both sexes, so on this basis, a prediction equation was established for Nepalese population.

Key words: Pulmonary function, Male, Female, Spirometry

\section{INTRODUCTION}

Spirometry is the measurement of air moving in and out of the lungs during various respiratory maneuvers. ${ }^{1}$ It plays a pivotal role in the diagnosis and monitoring of patients with respiratory disease. ${ }^{2}$ It is most commonly used in screening procedure in the studies involving patients with heart and lungs disease. Spirometry is easier to perform and even patients with heart and lungs disease can perform it when instructed properly by well-trained technician and/ or other health care provider.

The interpretation of spirometric results depend on comparison with reference values established according to age, sex, BMI, and ethinicity. ${ }^{3}$ Some of the important parameters like forced expiratory volume in one second $\left(F_{E V}\right)$, forced vital capacity $(\mathrm{FVC}), \mathrm{FEV}_{1} / \mathrm{FVC}$, peak expiratory flow rate (PEFR), maximum voluntary ventilation (MVV) are the key parameters generally used in the assessment and evaluation of respiratory disease. The normal values of pulmonary function test differ from one population to the other which has been established in the early 1970s by Woolcock and Co workers, in which they proposed that the pulmonary function test depends on ethnicity in addition to age, sex, height, weight, environmental condition. ${ }^{4}$ However, even after four decades, there is not much in the literature that highlights how different Nepalese population are from others. The clinical practice in respiratory medicine in Nepal is entirely relying on exotic normal reference values and we do not 
know how well that reflects the lung capacity of Nepalese population. In order to address this question and speculate the difference in the trends of spirometric reference values of Nepalese population, we designed this study. We also aimed to establish normative data of lung function indices $\left(\mathrm{FEV}_{1}, \mathrm{FVC}, \mathrm{FEV}_{1} / \mathrm{FVC}\right.$, PEFR and MVV) of healthy adult persons. Further, we elected to shed light on correlation of these data, if any, with age, height, weight and BMI.

This research has important values as the research on pulmonary function test in Nepal is limited. There has been few study on effect of sports, occupational dust, bronchial asthma on pulmonary function however study on pulmonary function of medical students and their anthropometric relation seems to be scanty. ${ }^{5-7}$ Moreover there was a study done on assessment of pulmonary function test of students of age group 5-25 years. However, this group only look at PEFR, which on itself does not carry any diagnostic significance these days. ${ }^{8}$

\section{MATERIALS AND METHODS}

This study involved recruitment of 174 students aged (mean age 19.60土1.177 yrs). Informed consent was obtained from all participants. All subjects were screened by means of a self-administered health questionnaire to exclude cardiopulmonary or other diseases that might affect pulmonary function. Specifically, subjects with a history of smoking, asthma, chronic bronchitis, chronic cough, exposure to any toxic chemicals, or surgery involving the chest wall were not eligible. Their height, weight, age, sex, presence of any respiratory symptoms/diseases, history of smoking was documented using a standard case history sheet. Ambient temperature was also recorded. Weight was recorded in $\mathrm{kg}$ and height was measured in $\mathrm{cm}$ without shoes while standing erect.

\section{For BMI calculation}

The BMI $\left(\mathrm{kg} / \mathrm{m}^{2}\right)$ was calculated as weight (in kilograms) divided by square of the height (in meters).

\section{For pulmonary function test (PFT)}

Pulmonary function test was performed using spirometer ('MEDSPIROR' RMS recorder and medicare system, Chandigarh, India) between 9 and12 a.m. All Subjects underwent spirometry tests, using techniques recommended by the American Thoracic Society (ATS). ${ }^{9}$ Age, sex, weight, height of the subject and the ambient temperature was recorded and fed in the spirometer too. Subject was instructed to take a deep breath and blow into the mouth piece as quickly and forcefully as possible. A nasal clip was applied over the nose to ensure the breathing through mouth alone. Subject was also instructed to fix his lips around the mouth-piece very tightly. Forced expiratory volume in one second $\left(\mathrm{FEV}_{1}\right)$, forced vital capacity $(\mathrm{FVC})$, $\mathrm{FEV}_{1} / \mathrm{FVC}$, peak expiratory flow rate (PEFR), were measured. The maximum voluntary ventilation (MVV) was determined by fast, deep breathing for a 10-second period and reported as litres/minute. The measure source of error can be on the maneuver done in instrument, so three reading were taken and best of three was taken for analysis.

\section{Statistical analysis}

Statistical analysis was performed using SPSS 16.0 (Statistical Program for the Social Sciences) for Windows. The data of all the variables were expressed in terms of mean \pm standard deviation. Pearson coefficient was used to find correlation between pulmonary parameters and physical parameters. The result was consider statistically significant if $\mathrm{p}$ value $<0.01$ and $<0.05$. Linear regression analysis was performed to see the relationship between pulmonary parameters and physical parameters.

\section{RESULTS}

The physical characteristics of male and female are given in Table 1. Comparisons of pulmonary parameters between male and female are shown in Table 2. Among pulmonary parameters, FVC, $\mathrm{FEV}_{1}$, PEFR and MVV were significantly higher in males than in females $(\mathrm{p}<0.01)$. However the ratio $\mathrm{FEV}_{1} / \mathrm{FVC}$ was higher in females but statistically not significant.

Pearson correlation of pulmonary parameters with physical characteristics of males and females of this study are presented in Table 3 and 4. It was observe that pulmonary parameters correlated significantly with physical characteristics of females except the ratio $\mathrm{FEV}_{1} /$

\begin{tabular}{|c|c|c|c|}
\hline Parameters & Male $(n=103)$ & Female $(n=71)$ & Total $(n=174)$ \\
\hline Age (yrs) & $19.79 \pm 1.355$ & $19.34 \pm 0.792$ & $19.60 \pm 1.177$ \\
\hline Height $(\mathrm{cm})$ & $167.16 \pm 5.998$ & $154.21 \pm 5.348$ & $161.87 \pm 8.572$ \\
\hline Weight (kg) & $63.70 \pm 10.651$ & $51.32 \pm 7.225$ & $58.65 \pm 11.190$ \\
\hline $\operatorname{BMI}\left(\mathrm{kg} / \mathrm{m}^{2}\right)$ & $22.75 \pm 3.227$ & $21.59 \pm 2.947$ & $22.28 \pm 3.159$ \\
\hline
\end{tabular}

\begin{tabular}{|c|c|c|c|}
\hline Parameters & Male $(n=103)$ & Female $(n=71)$ & $P$ value \\
\hline FVC (L) & $3.58 \pm 0.7241$ & $2.52 \pm 0.50$ & 0.001 \\
\hline $\mathrm{FEV}_{1}(\mathrm{~L})$ & $3.34 \pm 0.61$ & $2.44 \pm 0.44$ & 0.001 \\
\hline $\mathrm{FEV}_{1} / \mathrm{FVC} \%$ & $93.99 \pm 5.63$ & $95.91 \pm 11.03$ & 0.135 \\
\hline PEFR (L/sec) & $8.41 \pm 1.20$ & $6.72 \pm 0.82$ & 0.001 \\
\hline MVV (L/min) & $141.45 \pm 18.54$ & $106.93 \pm 12.49$ & 0.001 \\
\hline
\end{tabular}




\begin{tabular}{|c|c|c|c|c|}
\hline Variables & Height & Weight & Age & BMI \\
\hline FVC (L) & $0.490^{* *}$ & $0.399^{* *}$ & 0.123 & 0.157 \\
\hline $\mathrm{FEV}_{1}(\mathrm{~L})$ & $0.460^{* *}$ & $0.349^{* *}$ & 0.097 & 0.121 \\
\hline $\mathrm{FEV}_{1} / \mathrm{FVC}(\%)$ & -0.021 & 0.002 & 0.001 & 0.017 \\
\hline PEFR (L/sec) & 0.024 & $0.328^{* *}$ & 0.111 & $0.331^{* *}$ \\
\hline MVV (L/min) & 0.144 & $0.271^{*}$ & 0.195 & 0.196 \\
\hline
\end{tabular}

\begin{tabular}{|c|c|c|c|c|}
\hline Variables & Height & Weight & Age & BMI \\
\hline FVC (L) & $0.355^{\star *}$ & $0.345^{\star *}$ & -0.048 & $0.222^{*}$ \\
\hline $\mathrm{FEV}_{1}(\mathrm{~L})$ & $0.246^{*}$ & 0.167 & -1.31 & 0.066 \\
\hline $\mathrm{FEV}_{1} / \mathrm{FVC}(\%)$ & -0.120 & -0.176 & -0.029 & -0.148 \\
\hline PEFR (L/sec) & 0.163 & 0.073 & -0.049 & -0.003 \\
\hline MVV (L/min) & $0.311^{* *}$ & 0.142 & -0.104 & -0.007 \\
\hline
\end{tabular}

0.01 level of significance** and 0.05 level of significance*

FVC. FVC and $\mathrm{FEV}_{1}$ correlated significantly with height and weight $(\mathrm{p}<0.01)$. PEFR correlated with weight and BMI and MVV correlated with weight $(\mathrm{p}<0.05)$ (Table 3). On the other hand, in males, significant correlation of pulmonary parameters with physical characteristics was observed. FVC correlated with height $(p<0.01)$, weight $(p<0.01)$ and BMI $(p<0.05) . F E V_{1}$ and MVV correlated significantly with height 0.05 and 0.01 level of significance respectively. There was no significant correlation of PEFR and $\mathrm{FEV}_{1} / \mathrm{FVC}$ ratio with physical characteristics of male (Table 4).

\section{DISCUSSIONS}

The main results of our study showed that the mean FVC, $F_{1}$, PEFR and MVV of male were significantly higher than female. It was observed that pulmonary parameters correlate significantly with physical characteristics of males and females except the ratio $\mathrm{FEV}_{1} / \mathrm{FVC}$. An increasing number of pulmonary function studies have demonstrated that there exist significant variation between male and female lung functions and values in boys were significantly higher as compared to that of girls. ${ }^{10}$ For population of age 17-27 in Ethiopia, all the parameters decreases in female as compared to male. ${ }^{11}$ In a study done by Gupta and Gupta, the mean values of all pulmonary function measurements were higher in boys as compared to girls but statistically significant difference $(\mathrm{p}<0.001)$ was found for FVC and $\mathrm{FEV}_{1}{ }_{12}$ The reasons behind these variations might be hormones, structural and morphological differences. Increased estrogens levels tend to increase fluid retention and therefore increase blood volume, which could potentially affect gas exchange in the lung. In addition, progesterone and estrogens receptors have recently been identified in mast cells in human airways. This discovery may help to explain and account for some of the effects of sex hormones in airway function and differences in ventilation. ${ }^{13}$

In a study done by A Bandyopadhyay, the pulmonary function measurements exhibited significantly higher values among males than the females. Female FEV $1 \%$ didn't show any significant intergroup variation which is similar to our study where $\mathrm{FEV}_{1} \%$, in female was greater than male which was not significant. ${ }^{14}$ Mead suggested the gender differences in pulmonary function can be explained by smaller-diameter airways relative to lung size, and these differences probably become significant relatively late in the growth period of the lung. ${ }^{15}$ Even when corrected for sitting height relative to men adult women have smaller lung volumes and lower maximal expiratory flow rates. ${ }^{16} \mathrm{It}$ was found that mature men have a larger lung size brought about by a greater number of alveoli relative to that in mature women. ${ }^{17}$

In our study, maximum positive correlation of height occurred with $\mathrm{FEV}_{1}$ and $\mathrm{FVC}(\mathrm{r}=0.702$ and $0.687, \mathrm{p}<0.01)$ and of weight occurred with $\mathrm{FVC}$ and $\mathrm{FEV}_{1}(\mathrm{r}=0.58$ and $0.55, \mathrm{p}<0.01)$. BMI showed strong correlation with FVC. In a study done by Sandeep, the three independent variables (age, weight and height) have linear positive correlation with lung function parameters, both for boys and girls. Among all anthropometric parameters, height was the most independent variable with maximum coefficient of correlation. ${ }^{10}$ There was significant positive correlation with different parameters like height $(p<0.001)$, weight and BSA. ${ }^{18}$ In our study, maximum correlation of height occurred with FVC in female which is similar to a study done by Ayub M, in which he showed that there was a significant correlation of maximal flow rates with age and height. ${ }^{19}$ Gupta and Gupta found positive correlation of FVC, FEV ${ }_{1}$, and FEF25-75\% with age, height, BSA and BMI. ${ }^{12}$ In our study, FVC showed maximum correlation with height and weight and PEFR showed maximum correlation with BMI among females and among males FVC showed maximum correlation with height, weight and BMI. Amit Bandyopadhyay also showed that FVC and $\mathrm{FEV}_{1}$ exhibited significant correlations with body height and body mass among males whereas in the females exhibited significant correlation with body mass, body weight and also with age. ${ }^{14}$

Our study showed that among pulmonary parameters only FVC showed correlation with age $(r=0.163, \mathrm{p}<0.05)$, other parameters are correlated but are not significant. On contrary 
to our study, Singh R, in his research showed FVC and $\mathrm{FEV}_{1}$ negatively correlated with age. ${ }^{20}$ Ruivo also showed pulmonary parameters correlate negatively with age. ${ }^{21}$ Pruthi showed FVC, FEV 1 , PEFR, FEV 1 /FVC, SVC and MVV were found to be negatively correlated with age $(\mathrm{r}=-0.446$, $-0.495,-0.427,-0.312,-0.392$ and -0.919 , respectively). ${ }^{22}$ In a study lead by Memon, M. A., et al. (2007), negative correlation exist between pulmonary function and age. ${ }^{23}$

In our research, age showed negative correlation with pulmonary parameters of male and positive correlation with pulmonary parameters of female but they are not statistically significant. In spirometry performed on 614 female subjects ranging in age from 13 to 69 years and comprising all the main races in Malaysia, both FVC and $\mathrm{FEV}_{1}$ correlated negatively with age. ${ }^{24}$ Similarly, spirometry performed on 1,485 male subjects ranging in age from 13 years to 78 years, FVC and $\mathrm{FEV}_{1}$ showed negative correlation with age. ${ }^{20}$ The reason of positive correlation in our study might be similar age group of medical students.

\section{CONCLUSION}

From our study it can be concluded that pulmonary function parameters for male is higher than female in

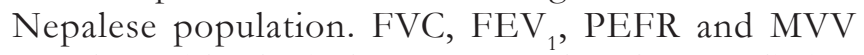
correlate with physical parameters therefore prediction equation is calculated below using simple regression which can be used to estimate pulmonary function in Nepalese population.

$$
\begin{aligned}
& \text { Predicted equation for females } \\
& F V C=0.046 \times \text { Height }-4.543 \\
& F E V_{1}=0.039 \times \text { Height }-3.554 \\
& P E F R=0.046 \times \text { Weight }+3.503 \\
& M V V=0.611 \times \text { Weight }+70.687 \\
& \text { Predicted equation for males } \\
& F V C=0.043 \times \text { Height }-3.685 \\
& F E V_{1}=0.031 \times \text { Height }-1.976 \\
& M V V=1.364 \times \text { Height }-80.549
\end{aligned}
$$

Further research in this area can be done to collect more normative data and to understand relative role of various factors like age, weight, height, races, environmental factors that affect lung function.

\section{ACKNOWLEDGEMENTS}

We gratefully acknowledge MBBS and BDS students of KIST medical college for participating in the research. We are very thankful to KIST medical college to provide the opportunity to carry out this research.

\section{REFERENCES}

1. Crapo RO. Pulmonary-function testing. N Engl J Med 1994; 331:25-30.

2. Golshan M, Nematbakhsh M, Amra B and Crapo RO. Spirometric reference values in a large Middle Eastern population. Eur Respir J 2003; 22(3):529-534.

3. García-Río F, Pino JM, Dorgham A, Alonso A and Villamor J. Spirometric reference equations for European females and males aged 65-85 yrs. Eur Respir J 2004; 24(3):397-405.

4. Woolcock AJ, Colman MH and Blackburn CR. Factors affecting normal values for ventilatory lung function. Am Rev Respir Dis 1972; 106(5):692-709.

5. Prajapati R, Shrestha B, Dhungel S, Devkota K. C, Pramanik $T$ and Roychowdhury P. Spirometric evaluation of pulmonary function tests in clinically diagnosed patients of bronchial asthma. Nepal Med Coll J 2010; 12(1): 45-47.

6. Mahotra N B and Shrestha L. Effects of Type Sports on Pulmonary Function Tests: A Comparative Study In Nepalese Settings. Journal of Nobel Medical College 2013; 2.1: 18-21.

7. Das P. K. L and N. Jha. Occupational exposure and pulmonary function of jute mill workers in Sunsari, Nepal. Nepal Med Coll J 2009; 11(4):275-277.

8. Dhungel KU, Parthasarathy D and Dipali S. Peak expiratory flow rate of Nepalese children and young adults. Kathmandu University Medical Journal 2008; 6(3): 346-354.

9. Standardisation of spirometry. Series ATS/ERS Task Force: Standardisation of lung function testing. Edited by V. Brusasco, R. Crapo and G. Viegi. Eur Respir J 2005; 26: 319-338.

10. Budhiraja S, Singh D, Pooni A P and Dhooria G S, Pulmonary Functions in Normal School Children in the Age Group of 615 Years in North India. Iran J Pediatr Mar 2010; 20(1):82-90.

11. Mengesha $Y A$ and Mekonnen $Y$. Spirometric lung function tests in normal non-smoking Ethiopian men and women. Thorax 1985; 40: 465-468.

12. Gupta and Gupta: Allied health - 3004. Pulmonary function tests: A study of 1000 normal children. World Allergy Organization Journal 2013 6(Suppl 1):P181.

13. Craig A. Harms. Does gender affect pulmonary function and exercise capacity? Respiratory Physiology \& Neurobiology 2006; 151:124-131.

14. Bandyopadhyay A. Pulmonary function studies in young healthy Malaysians of Kelantan, Malaysia. Indian J Med Res 2011; 134: 653-657.

15. Mead J. Dysanapsis in normal lungs assessed by the relationship between maximal flow, static recoil, and vital capacity. Am Rev Respir Dis 1980;121:339-342.

16. Crapo RO, Morris $\mathrm{AH}$ and Gardner RM. Reference values for pulmonary tissue volume, membrane diffusing capacity, and pulmonary capillary blood volume. Bull. Eur. Physiolopathol. Respir 1982; 18:893-899.

17. Thurlbeck W.M. Post natal human lung growth. Thorax 1982;37:564-571.

18. Prajapati R. Assessment of pulmonary function in local healthy Nepalese men of Dharan and it's anthropometric correlation. Nepal Med Coll J 2007; 9(3):191-195.

19. Ayub M, Zaidi SH and Burki NK. Spirometry and flow-volume curves in healthy, normal Pakistanis. Br J Dis Chest 1987; 81(1):35-44.

20. Singh R, Singh HJ and Sirisinghe RG. Spirometric volumes in Malaysian males. Southeast Asian J Trop Med Public Health 1994; 25(2):341-348.

21. Susana R, Viana P, Martins $C$ and Baeta $C$. Effects of aging on lung function. A comparison of lung function in healthy adults and the elderly. Revista Portuguesa de Pneumologia (English 
Edition) 15, no. 4 (2009): 629-653.

22. Pruthi $\mathrm{N}$ and Multani N. Influence of Age on Lung Function Tests. Journal of Exercise Science and Physiotherapy 2012; 8(1):1-6.

23. Memon MA, Sandila MP and Ahmed ST. Spirometric reference values in healthy, non-smoking, urban Pakistani population. JPMA 2007; 57(4):193-195.

24. Singh R, Singh HJ, Sirisinghe RG. Spirometric volumes in Malaysian females. Jpn J Physiol 1992; 42: 407-414.

Authors Contribution:

GBN - data collection, analysis, writing and computer works; PKLD - data collection, analysis, writing; AB - data collection, computer work; All the authors have prepared, read and approved the paper.

Source of Support: Nil, Conflict of Interest: None declared. 